\title{
PERILAKU TANTRUM PADA ANAK USIA DINI DI SEKOLAH
}

\author{
Cau Kim Jiu ${ }^{1}$, Hartono ${ }^{2}$, Lince Amelia ${ }^{3}$, Surtikanti ${ }^{4}$, Tisa Gusmiah ${ }^{5}$, Wuriani ${ }^{6}$, Usman $^{7}$, Kharisma Pratama $^{8}$, \\ Gusti Jhoni Putra9 \\ Prodi Keperawatan, Sekolah Tinggi Ilmu Keperawatan Muhammadiyah Pontianak \\ Email: ckj@stikmuhptk.ac.id ${ }^{1}$.hartono@stikmuhptk.ac.id², lince@stikmuhptk.ac.id ${ }^{3}$, \\ surtikanti@stikmuhptk.ac.id ${ }^{4}$, tisa@stikmuhptk.ac.id ${ }^{5}$,wuriani@ stikmuhptk.ac.id6, \\ usmanudan@stikmuhptk.ac.id ${ }^{7}$, charisma@stikmuhptk.ac.id ${ }^{8}$, gustijhoni@stikmuhptk.ac.id ${ }^{9}$
} Jiu, C.K, dkk (2021). Perilaku Tantrum Pada Anak Usia Dini di Sekolah. Jurnal Pelita PAUD, 5(2), 262-267. doi: https://doi.org/10.33222/pelitapaud.v5i2.1317

Abstrak: Penelitian ini bertujuan untuk mengidentifikasi bentuk-bentuk tantrum dan pemicu tantrum pada anak usia dini di sekolah. Metode yang digunakan dalam penelitian ini adalah deskriptif kuantitatif dengan menggunakan angket dalam pengumpulan data yang disebarkan secara online pada 101 guru PAUD dan TK 'Aisyiyah Bustanul Athfal di 14 Kabupaten Kalimantan Barat. Analisis data yang digunakan dalam penelitian ini menggunakan analisis deskriptif persentase. Hasil penelitian menunjukkan bahwa pemicu tantrum pada anak usia dini di sekolah 33,7 \% disebabkan oleh keinginan anak yang tidak dipenuhi dengan bentuk perilaku tantrum yang ditunjukkan $28,7 \%$ yaitu dengan cara menangis. Cara guru menenangkan anak tantrum di sekolah 18,8\% dengan cara memeluk anak. Meskipun perilaku tantrum merupakan perilaku yang biasa terjadi pada anak usia dini di sekolah namun para guru harus mengenal dan dapat mengatasi perilaku tantrum yang muncul pada anak sehingga kedepannya diperlukan pelatihan bagi guru dalam menangani anak dengan tantrum di sekolah.

Kata Kunci: Tantrum, Perilaku, Anak Usia Dini, Sekolah

Abstract: This study aims to identify the forms of tantrums and triggers of tantrums in early childhood at school. The method used in this research is descriptive quantitative using questionnaires in collecting data distributed online to 101 PAUD and TK 'Aisyiyah Bustanul Athfal teachers in 14 districts of West Kalimantan. Analysis of the data used in this study used descriptive percentage analysis. The results showed that the trigger for tantrums in early childhood in school $33.7 \%$ was caused by the desire of children who were not fulfilled by the form of tantrum behavior shown by $28.7 \%$, namely by crying. The teacher's way of calming tantrums at school is $18.8 \%$ by hugging the child. Although tantrum behavior is a behavior that usually occurs in early childhood at school, teachers must recognize and be able to overcome tantrum behavior that appears in children so that in the future training is needed for teachers in dealing with children with tantrums at school.

Keywords: Tantrum, Behaviors, Early Childhood, School

(C) 2021 Cau Kim Jiu, Hartono, Lince Amelia, Surtikanti, Tisa Gusmiah, Wuriani, Usman, Kharisma Pratama, Gusti Jhoni Putra Under the license CC BY-SA 4.0

http://jurnal.upmk.ac.id/index.php/pelitapaud 


\section{PENDAHULUAN}

Temper tantrum merupakan respons yang normal terhadap kemarahan dan umumnya terjadi pada anak berusia antara satu hingga empat tahun. Respon ini muncul sebagai upaya dari kegagalan anak dalam melatih penguasaan diri dan pengambilan keputusan. Tantrum lebih sering terjadi pada anak yang aktif dan memiliki keinginan yang tinggi serta energi yang berlebih. Praktik pengasuhan anak yang dapat mendorong perilaku tantrum pada anak termasuk inkonsistensi dalam pengasuhan, ekspektasi yang tidak masuk akal, keketatan yang berlebihan, terlalu protektif, dan terlalu memanjakan. Orang tua dan guru perlu memahami perilaku anak baik di rumah maupun di sekolah agar dapat mengatasi perilaku tantrum pada anak. Perilaku tantrum sebaiknya di tangani setelah amarah anak mereda. Orang tua dan guru membantu anak untuk belajar mengungkapkan perasaan negatif dan rasa marah dengan cara yang lebih positif (Leung \& Fagan, 1991). Tiga kategori perilaku tantrum yang dapat muncul pada anak meliputi agresi destruktif, agresi nondestruktif, dan distress namun saat tantrum anak hanya menunjukkan salah satu dari ketiga kategori perilaku ini. Ketidakpatuhan memicu 52\% tantrum pada anak. Perilaku agresif lebih mungkin terjadi di awal tantrum kemudian disusul dengan distress perilaku (Eisbach dkk, 2014)

Setiap hari guru dihadapkan pada berbagai macam perilaku anak dikelas. Mengelola perilaku anak di kelas merupakan tantangan bagi para guru. Kurangnya pemahaman guru di sekolah terkait penanganan tantrum menyebabkan perilaku ini semakin berkembang Menurut Daniels, Mandleco dan Luthy (2012) temper tantrum merupakan salah satu masalah perilaku yang paling umum pada anak-anak. Hasil penelitian Potegal, Kosorok, dan Davidson (2003) pada 335 anak yang berusia 18 sampai 60 bulan ditemukan bahwa durasi tantrum yang paling umum adalah 0,5 hingga 1 menit, $75 \%$ dari tantrum berlangsung 5 menit atau kurang. Prevalensi tantrum ditemukan meningkat dari $87 \%$ pada 18 sampai 24 bulan menjadi $91 \%$ pada 30 sampai 36 bulan dan kemudian menurun menjadi $59 \%$ pada 42 hingga 48 bulan (Potegal \& Davidson, 2003). Hasil wawancara awal dengan beberapa guru di TK dan PAUD menunjukkan bahwa guru mengalami kesulitan dalam menenangkan perilaku tantrum pada anak dan butuh waktu lebih dari 30 menit dalam menenangkan anak dengan tantrum. Peran guru sangat penting dalam menenangkan anak tantrum di sekolah. Hasil penelitian Rahmaningrum dan Fauziah (2020) menyebutkan bahwa ketika guru sudah memiliki kedekatan dengan anak, maka guru dapat mengetahui kemampuan serta hal yang belum dikuasai oleh anak. Kedekatan tersebut tidak hanya dekat secara fisik namun kedekatan secara psikis sehingga guru dapat memahami anak didiknya secara baik. Guru menciptakan suasana kelas yang nyaman serta menyenangkan bagi seluruh anak, hal ini juga menambahkan hal yang positif bagi anak tersebut. Hasil penelitian Indanah dan Karyati (2017) menunjukkan bahwa ada hubungan antara lingkungan sekolah dengan reaksi temper tantrum.

Hasil penelitian ini memberikan gambaran bahwa guru harus mampu mengendalikan perilaku anak di sekolah sehingga pengetahuan guru dalam mengelola perilaku siswa sangat penting. Pengetahuan guru yang baik tentang manajemen perilaku tantrum dapat membantu guru menangani dalam berbagai masalah tingkah laku murid di kelas. Guru di tuntut untuk sensitif dan mengenali tingkah laku murid sehingga dapat menggunakan teknik yang tepat dalam menangani masalah perilaku tantrum pada siswa di sekolah.

Berdasarkan latar belakang ini peneliti tertarik untuk mengidentifikasi bentuk-bentuk tantrum serta faktor pemicu tantrum pada anak usia dini disekolah serta tindakan yang dilakukan oleh guru di sekolah saat melihat anak tantrum.

\section{METODE PENELITIAN Jenis Penelitian}

Jenis penelitian yang digunakan dalam penelitian ini yaitu deskriptif kuantitatif. Penelitian ini hanya mendeskripsikan atau memaparkan variabel yang diteliti namun tidak menganalisa hubungan antar variabel yang ada. 


\section{Waktu dan Tempat Penelitian}

Penelitian ini dilakukan pada bulan Desember 2020 secara online di PAUD dan TK AisyiyahBustanul Athfal di 14 Kabupaten/Kota Provinsi Kalimantan Barat.

\section{Subjek Penelitian}

Sampel dalam penelitian ini adalah guru yang mengajar di PAUD dan TK 'Aisyiyah Bustanul Athfal yang berjumlah 101 guru dengan tehnik pengambilan sampel menggunakan purposive sampling.

\section{Prosedur}

Prosedur dalam penelitian ini yaitu meminta responden mengisi angket yang disediakan terlebih dahulu peneliti menjelaskan maksud dan tujuan penelitian dan meminta kesediaan responden secara sukarela untuk berpartisipasi dalam penelitian ini. Instrumen penelitian di isi secara online oleh para guru yang mengajar di PAUD dan TK 'Aisyiyah Bustanul Athfal Pimpinan Wilayah 'Aisyiyah Kalimantan Barat. Setiap responden hanya mengisi dan memilih satu jawaban yang tersedia. Angket berisi pertanyaan singkat mengenai bentuk perilaku tantrum peserta didik di kelas, pemicu perilaku tantrum pada peserta didik, dan tindakan yang dilakukan oleh guru saat anak menunjukkan perilaku tantrum.

\section{Data, Intrumen, dan Teknik Pengumpulan Data}

Teknik pengumpulan data dapat dilakukan dalam berbagai setting, berbagai sumber, dan berbagai cara. Teknik pengumpulan data yang digunakan dalam penelitian ini dilaksanakan dengan teknik wawancara, observasi, telaah dokumen dan angket.

\section{Teknik Analisis Data}

Analisis data yang digunakan dalam penelitian ini menggunakan analisis deskriptif persentase yaitu hasil yang di dapatkan seperti bentuk-bentuk tantrum, pemicu tantrum dan cara guru menangani tantrum di sajikan dalam bentuk persentase.

\section{HASIL PENELITIAN PEMBAHASAN}

DAN

Penelitian ini diikuti oleh 101 guru sebagai responden yang mengajar di PAUD dan TK Aisyiyah Bustanul Athfal Pimpinan Wilayah Aisyiyah Kalimantan Barat. Adapun karakteristik responden sebagai berikut:
Tabel 1. Karakteristik Responden Menurut Usia, Masa Kerja, dan Pendidikan di PAUD dan TK 'Aisyiyah Bustanul Athfal PWA Kalbar

\begin{tabular}{lcc}
\hline \multicolumn{1}{c}{ Karakteristik } & F & $\%$ \\
\hline Usia & & \\
$17-25$ tahun & 8 & 7,9 \\
$26-35$ tahun & 35 & 34,7 \\
$36-45$ tahun & 38 & 37,6 \\
$46-55$ tahun & 16 & 15,8 \\
$56-65$ tahun & 4 & 4 \\
\hline Masa Kerja & & \\
$1-5$ tahun & 31 & 30,6 \\
$6-10$ tahun & 30 & 29,7 \\
$11-15$ tahun & 15 & 14,9 \\
$>15$ tahun & 25 & 24,8 \\
\hline Pendidikan & & \\
SMA / Sederajat & 34 & 33,7 \\
Diploma & 8 & 7,9 \\
Sarjana & 59 & 58,4 \\
Total & 101 & 100 \\
\hline
\end{tabular}

Berdasarkan tabel 1 menunjukkan bahwa rata-rata usia guru yang mengajar di PAUD dan TK 'Aisyiyah Bustanul Athfal Pimpinan Wilayah 'Aisyiyah Kalimantan Barat berusia 36-45 tahun yaitu 38\% dengan masa kerja 1-5 tahun sekitar $30,7 \%$ dan berpendidikan sarjana $58,4 \%$.

\section{Bentuk Perilaku Tantrum}

Hasil penelitian menunjukkan bahwa berbagai perilaku tantrum yang sering kali di tunjukkan oleh peserta didik di sekolah sebagaimana yang di tunjukan oleh tabel 2 di bawah ini:

Tabel 2. Bentuk Perilaku Tantrum di Kelas Pada Anak di PAUD dan TK 'Aisyiyah Bustanul Athfal PWA Kalbar

\begin{tabular}{lcc}
\hline \multicolumn{1}{c}{ Bentuk Tantrum } & F & $\%$ \\
\hline Menangis & 29 & 28,7 \\
Menjerit/Berteriak & 16 & 15,8 \\
Berguling-guling & 16 & 15,8 \\
Memukul teman & 9 & 8,9 \\
Mengamuk & 8 & 7,9 \\
Membenturkan kepala & 4 & 4,0 \\
Membanting kursi & 4 & 4,0 \\
Memukul guru & 3 & 3,0 \\
Melempar barang & 3 & 3,0 \\
Menghentakkan kaki & 3 & 3,0 \\
Membanting pintu & 2 & 2,0 \\
Menggigit & 2 & 2,0 \\
Baring di lantai & 2 & 2,0 \\
Total & 101 & 100 \\
\hline
\end{tabular}


Berdasarkan tabel 2 menunjukkan bahwa bentuk perilaku tantrum yang paling sering terjadi pada anak di kelas yaitu menangis sebesar $28,7 \%$, menjerit atau berteriak $15,8 \%$, berguling-guling di lantai $15,8 \%$, memukul teman $8,9 \%$ dan mengamuk 7,9\%. Hasil penelitian ini sejalan dengan penelitian yang dilakukan oleh Wulansari (2015) yang menjelaskan bahwa terdapat dua anak tantrum di salah satu taman kanak-kanak dengan perilaku yaitu : 1) menangis, 2) menendang, 3) memukul, 4) berteriak-teriak, serta 5) melempar benda. Menurut Eisbach dkk (2014) ada 3 kategori perilaku tantrum yang dapat muncul yaitu destructive aggression, nondestructive aggression, dan distress behaviors. Perilaku agresif lebih mungkin terjadi terjadi di awal tantrum, kemudian disusul dengan distress behaviors. Pendapat sebelumnya dari Belden dkk. (2008) yang mengidentifikasi beberapa perilaku agresif yang di lakukan oleh anak seperti menyakiti diri sendiri dan orang lain, memukul, menendang, menggigit, melempar, melukai diri sendiri. Sedangkan perilaku yang tidak destruktif seperti berteriak atau menjerit. Lebih lanjut menurut Potegal (2000) distress perilaku yang muncul pada anak merupakan reaksi dari sistem saraf pusat sehingga mengakibatkan anak berkeringat, menangis, meneteskan air liur dan kadang-kadang wajah memerah.

Setiap anak adalah unik dan mereka akan menunjukkan respon atau reaksi yang berbeda-beda dalam menyikapi perubahan lingkungan atau stimulus internal maupun eksternal. Namun seorang guru harus memahami respon tersebut agar dapat mengurangi perilaku agresif sehingga dapat mengelola perilaku tersebut menjadi perilaku yang adaptif

\section{Pemicu Tantrum di Sekolah}

Hasil penelitian menunjukkan bahwa pemicu anak menjadi tantrum di sekolah dapat berbeda-beda antara anak yang satu dengan yang lainnya. Berikut merupakan beberapa pemicu anak menjadi tantrum di sekolah sebagaimana di tunjukkan oleh tabel 3 berikut ini:
Tabel 3. Pemicu Perilaku Tantrum pada Anak di Kelas

\begin{tabular}{lcc}
\hline \multicolumn{1}{c}{ Pemicu Tantrum } & F & $\%$ \\
\hline Keinginan anak tidak & 34 & 33,7 \\
dipenuhi & 24 & 23,8 \\
Diganggu oleh teman & 15 & 14,9 \\
Barang diambil teman & 12 & 11,9 \\
Berebut mainan & 9 & 8,9 \\
Tidak mau di tinggal orang & & \\
tua & 7 & 6,9 \\
Tidak mau mengikuti instruksi & 101 & 100 \\
Total & \\
\hline
\end{tabular}

Berdasarkan tabel 3 diketahui bahwa pemicu terjadinya tantrum pada anak di sekolah adalah keinginan anak yang tidak terpenuhi yaitu $33,7 \%$, kemudian diganggu oleh teman $23,8 \%$ dan barangnya seperti pensil, buku atau makanan diambil oleh temanya. Hasil penelitian ini selaras dengan penelitian yang dilakukan oleh Wulansari (2015) yang menjelaskan bahwa terdapat dua anak tantrum di salah satu taman kanak-kanak yang berperilaku tantrum di sebabkan oleh 1) tidak terpenuhinya apa yang diinginkan, 2) merasa kecewa, 3) berebut mainan, 4) diganggu teman dan 5) jika dimarahi guru. Menurut Eisbach dkk (2014) 52\% tantrum terjadi akibat ketidakpatuhan anak. Menurut Bhatia dkk (1990) ada beberapa penyebab anak mengalami tantrum diantaranya masalah di dalam keluarga seperti tidak konsisten dalam penerapan disiplin, terlalu banyak mengkritik, orang tua terlalu protektif pada anak, kelalaian orang tua, kurang kasih sayang dan perhatian dari orang tua, orang tua yang mengalami masalah pernikahan, bertemu dengan orang asing, persaingan dengan saudara kandung, masalah bicara dan penyakit. Menurut Sembiring, Filtri dan Efastri (2017) tantrum dapat disebabkan oleh faktor fisiologis, psikologis, lingkungan dan pola asuh. Faktor fisiologis yang dapat memicu terjadinya tantrum pada anak seperti lapar, lelah atau sakit sedangkan faktor psikologis seperti anak yang mengalami kegagalan, orang tua yang terlalu menuntut anak agar sesuai dengan harapan orang tua.

Menurut peneliti perilaku tantrum anak di sekolah karena salah satunya adalah faktor lingkungan. Anak mengalami perubahan situasi dari lingkungan rumah ke lingkungan di luar rumah sehingga menyebabkan perubahan perilaku dan suasana hati anak 
yang tadinya bersama dengan orang tua atau keluarga di rumah namun saat ini harus berada di lingkungan baru yang memiliki aturan dan norma tersendiri sehingga situasi ini dapat menimbulkan rasa stress dan luapan emosi anak yang kurang terkontrol

\section{Manajemen Tantrum di Kelas}

Setiap guru memiliki cara dan pendekatan yang berbeda dalam menenangkan murid yang sedang tantrum di kelas. Ini dapat dilihat dari hasil penelitian yang di tunjukkan pada tabel 4 di bawah ini:

Tabel 4. Cara Guru Mengatasi Anak Tantrum di Sekolah

\begin{tabular}{lcc}
\hline \multicolumn{1}{c}{$\begin{array}{c}\text { Cara Guru Mengatasi } \\
\text { Anak tantrum }\end{array}$} & F & $\%$ \\
\hline Memeluk anak & 19 & 18,8 \\
Mengelus bahu anak & 14 & 13,9 \\
Mengalihkan perhatian & 12 & 11,9 \\
Mengajak bermain & 10 & 9,9 \\
Mengajak anak berbicara & 8 & 7,9 \\
Menuruti keinginan anak & 7 & 6,9 \\
Membiarkan anak tenang & 6 & 5,9 \\
Membujuk anak & 6 & 5,9 \\
Menemani anak & 6 & 5,9 \\
Mencari tahu penyebab & 4 & 4 \\
Memijat anak & 3 & 3 \\
Dipisahkan dari teman & 3 & 3 \\
Dibawa ke ruangan lain & 3 & 3 \\
Total & 101 & 100 \\
\hline
\end{tabular}

Hasil penelitian sebagaimana yang di tunjukkan oleh tabel 4 diketahui bahwa beberapa cara yang dilakukan oleh guru dalam mengatasi anak dengan tantrum dikelas 18,8\% dengan memeluk anak, $13,9 \%$ mengelus bagian bahu anak, $11,9 \%$ mengalihkan perhatian anak, 9,9\% mengajak anak bermain dan 7,9\% mengajak anak bicara setelah anak tenang. Menurut Wulansari (2015) upaya yang dilakukan guru untuk mengatasi perilaku tantrum yaitu dengan 1) memberikan pujian, 2) menasehati dengan cerita, 3) menegur, 4) memberikan reward, 5) mengajarkan tanggungjawab, 6) mengalihkan perhatian anak serta 7) meminta teman lain untuk tidak mengganggunya.

Menurut peneliti, guru sebagai tenaga pengajar harus bisa memahami karakteristik anak agar mengetahui cara yang tepat dalam menangani tantrum. Guru di tuntut untuk bersikap tenang dan sabar dalam menghadapi anak dengan perilaku tantrum. Kasih sayang dan perhatian guru dapat memberikan rasa aman dan nyaman bagi anak didik sehingga perilaku anak dapat terkendali secara baik. Kemampuan guru dalam berkomunikasi

\section{SIMPULAN}

Tantrum terjadi akibat salah satu kebutuhan anak tidak terpenuhi. Meskipun perilaku tantrum merupakan hal yang wajar dalam tahap perkembangan emosional anak namun apabila perilaku tersebut tidak ditangani secara baik dan tepat maka dapat berpengaruh ke perkembangan sosial-emosional. Guru berperan sebagai orang tua di sekolah membawa pengaruh yang penting dalam membentuk karakter dan perilaku anak. Kasih sayang, perhatian, ketrampilan komunikasi dan kesabaran menjadi kunci keberhasilan bagi guru dalam menenangkan atau mengatasi anak yang sedang tantrum.

\section{DAFTAR PUSTAKA}

Aini, A. N., \& Hanifah, N. A. (2015). Tahap pengetahuan guru pendidikan khas apabila mengurus tingkah laku murid bermasalah pembelajaran. Asia Pacific Journal Educators and Education, 30(1), 73-88.

Bhatia, M. S., Dhar, N. K., Singhal, P. K., Nigam, V. R., Malik, S. C., and Mullick, D. N. (1990). Temper tantrums: Prevalence and etiology in a nonreferral outpatient setting. Clinical Pediatrics, 29, 311-315.

Belden, A.C., Thomson, N.R., \& Luby, J.L. (2008). Temper tantrums in healthy versus depressed and disruptive preschoolers: Defining tantrum behaviors associated with clinical problems. Journal of Pediatrics, 152, 117-122. doi:10.1016/j. jpeds.2007.06.030

Daniels E, Mandleco B, Luthy KE. (2012). Assessment, management, and prevention of childhood temper tantrums. J Am Acad Nurse Pract. 2012 Oct;24(10):569-73.

Eisbach, S. S., Cluxton-Keller, F., Harrison, J., Krall, J. R., Hayat, M., \& Gross, D. (2014). Characteristics of temper tantrums in preschoolers with disruptive behavior in a clinical setting. Journal of psychosocial nursing and mental health services, 52(5), $32-40$. 
Indanah, Karyati. (2017) Todler Temper Tantrum. The $5^{\text {th }}$ Urecol Proceeding. UAD Yogyakarya. 1300-1311.

Leung AK, Fagan JE.(1991). Temper tantrums. Am Fam Physician;44(2):559-63

Potegal M, Kosorok MR, Davidson RJ. (2003). Temper tantrums in young children: 2. Tantrum duration and temporal organization. J Dev Behav Pediatr. Jun;24(3):148-54. doi: 0196-206X/00/2403014

Potegal M, Davidson RJ. (2003). Temper tantrums in young children: 1. Behavioral composition. J Dev Behav Pediatr. Jun;24(3):140-7. doi: 0196-206X/00/24030140

Rahmaningrum A \& Fauziauh. P (2020), Peran Guru pada Pengasuhan Anak dari Keluarga Tenaga Kerja Indonesia. Jurnal Obsesi : Jurnal Pendidikan Anak Usia Dini, 5(2), 2021: $\quad 1282-1292, \quad$ DOI: 10.31004/obsesi.v5i2.796

Sembiring KA, dkk. (2017). Persepsi Orang Tua terhadap PemecahanMasalah Temper Tantrum Anak Usia Dini di Kecamatan Rumbai Kota Pekanbaru. Universitas Lancang Kuning. 92(4), 90-99. Diakses tanggal $6 \quad$ Mei 2021 dari https://repository.unilak.ac.id/122/1/288Research\%20Results-661-1-1020180220.pdf

Wulansari M (2015). Perilaku Tantrum Anak Usia 5-6 Tahun Di Tk Marditama Timbulharjo Sewon Bantul, Program Studi Pendidikan Guru Pendidikan Anak Usia Dini Jurusan Pendidikan Anak Usia Dini Fakultas Ilmu Pendidikan Universitas Negeri Yogyakarta.
Diakses tanggal 6 Mei 2021 dari https://core.ac.uk/download/pdf/33528577. pdf 